\title{
A message from the Editor in Chief
}

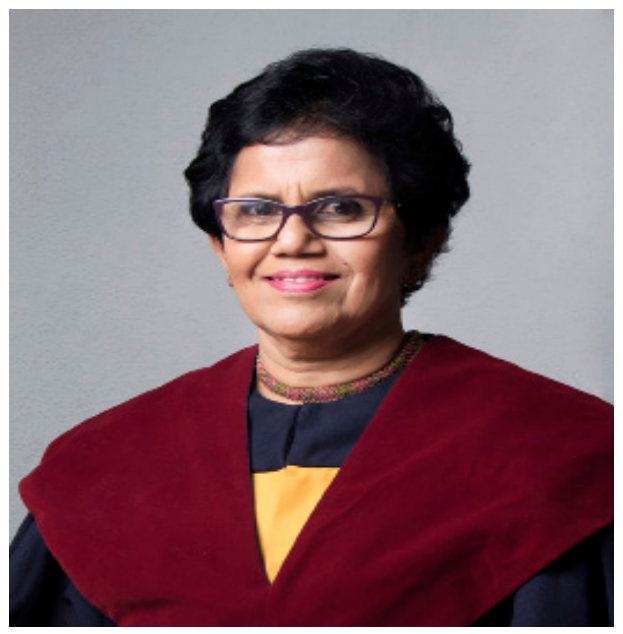

Dear authors, reviewers and readers of Sri Lanka Journal of Obstetrics and Gynaecology.

It gives me great pleasure to welcome you to the first issue of the Sri Lanka Journal of Obstetrics and Gynaecology 2018. The current issue (Volume 40, Issue 1) of SLJOG, consist of 2018 Presidential address, one oration and two research articles.

We are already indexed by DOAJ (Directory of Open Access Journals) and besides trying our best to reach the standard of a worthy scientific journal; several internal changes have been done. We rejuvenated our editorial board and over the year we also plan several new initiatives to make the journal more exciting and useful to our readers.

The review process places heavy demands on the Journal as well as on reviewers. A good review often is educational for authors and editors alike. When reviewers point to flaws that are reparable in a paper of interest, the Journal encourages authors to revise and resubmit and thus benefit from the insights gained.

Indeed, we increasingly experience difficulties in obtaining qualified referees who are willing to undertake reviews within a given period of time. Reviewers can take pride and comfort from the many authors who are moved to comment, when they submit revisions, about the considerable help they have had from our reviewers in recognizing weaknesses and improving the quality of their papers. These comments appear in cover letters are not always seen by the reviewers in question but as the editor, I can attest that they are frequent and consistently positive.

I would like to express special appreciation of the commitment of all our reviewers towards increasing the quality and presentation of research findings in the Journal.

I understand that the research community faces ever-growing pressures from a variety of sources: scarcity of funds and multiple demands on time.

Please plan to submit your own cutting edge research to SLJOG and thus ensure that your articles reach the diverse knowledgeable and global readership that they deserve.

\section{Ramya Pathiraja}

Editor in Chief,

Sri Lanka Journal of Obstetrics and Gynaecology

DOI: http:// doi.org/10.4038/sljog.v40i1.7837 